\title{
Effect of The Tilt Angles on The Power Generation of The Small Manufactured Dual Wind Turbine Equipped By Separation Mechanism and Rotation Reversing Device
}

\author{
Dr. Muhannad Z. Khalefa ${ }^{\dagger}$, Dr. Shereen F. Abd Alkarim ${ }^{\ddagger}$ and Rasha S. Salih ${ }^{\dagger}$ \\ $\dagger$ Department of Electromechanical Engineering, University of Technology, Baghdad-Iraq. \\ Department of Electromechanical Engineering, University of Technology, Baghdad-Iraq \\ ${ }^{\dagger}$ Department of Electromechanical Engineering, University of Technology, Baghdad-Iraq.
}

\begin{abstract}
Due to the importance of generating electricity from wind turbines, single rotor wind turbine and dual rotor wind turbine, there was a need to design and manufacture the turbine system operating in both types mentioned above and have advantages to increase the generation of electric power. The aim of this work was to generate electrical power at a wind speed of up to $1 \mathrm{~m} / \mathrm{s}$ and more to achieve this wind speed and direction of the wind were adopted from tables of the Zerbatiya Station of the Wasit Governorate. Controlling the work is by Adaptive Controller technology, as well as the programming language which used is Visual Studio 2015.

The simulation was used to generate rotational speed for front and rear blades from $1 \mathrm{~m} / \mathrm{s}$ to $13 \mathrm{~m} / \mathrm{s}$. Movable wings were placed in the manufactured system which rotate at angle of $0^{\circ}-14^{\circ}$ for the purpose of studying the effect of the tilt angle of the blades on power generation. The following were added to the system: mechanism to separate the work of the front and rear rotors and a device to reverse the rotation of these rotors. The Genetic Algorithm (GA) was used within the program for the purpose of obtaining the best of generated power. All the above were for the purpose of determining the best position for blades at different speeds to generate electricity by using Permanent Magnet Synchronous Generator $(400 \mathrm{~W})$. The maximum generated power in dual wind turbine (DWT) when rotate the front and rear blades in same direction was obtained at speed $(151 \mathrm{rpm})$ in used tilt angle of movable wing is about $\left(12^{\circ}\right)$ and power $(124.223 \mathrm{~W})$ also the separation mechanism and rotation reversing device proved efficiency.
\end{abstract}

Keywords: Dual wind turbine, genetic algorithm (GA), tilt angles, rotation reversing device, movable wing.

\section{Introduction}

Dual-rotor wind turbines (DRWT) are equipped with two co-axial rotors in a back-to-back configuration or with an upwind and downwind rotor separated by the nacelle. Since the shape of the inboard section of single rotor wind turbine (SRWT) blades extract little energy from the wind, it is hypothesized that by adding a smaller rotor upstream of a (SRWT), more energy can be harvested. Moreover, since the wake behind a rotor rotates in opposite direction to the rotor itself, more energy can be extracted by having the downwind rotor taking advantage of the wake rotation of the upwind rotor .In other words, counter rotating (DRWT) can harvest more energy as compared to corotating (DRWT) [1].

Designed a Contra Rotation Double Rotor Wind Turbine (CR-DRWT), composed of small-sized rear wind and large-sized front wind rotor at the same side. The (CRDRWT) depend on the wind speed. Because the (CRDRWT) has contra rotation rotor, so it can rotate relatively on adequate rpm, at moderate wind speed. The relative rotational speed remain constant, when the wind speed increased, even at high wind speed, it remains constant, the rear rotor is rotate by the front rotor and rotated at same direction. This kind of wind turbine has a selfregulating characteristics on the speed due to the difference in torque between two stages horizontal axis wind turbine, then no need pitch controller to control the speed , and cutting off the wind turbine due to high wind speed [2].

Select the best park arrangement of huge offshore turbine in a hurricane, the study is carried out on the effects of the blade pitch and rotor yaw, and irregularity of the wind wave. The results showed that the effects of the blade pitch and rotor yaw are important to the dynamics of turbine structural, while the effect of the irregularity of the wind wave is small in case of the structural design. This study stretch in a deep insight into the structural design and the dynamics of wind turbine [3], see Figure (1).

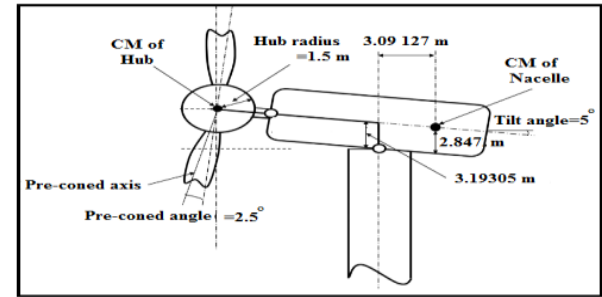

Fig.1 Rotor-Nacelle Assembly (RNA) of 13.2-MW Wind Turbine [3]. 
The control of the tilt angle is the most common way to adjust the aerodynamic torque of a wind turbine when rating wind speed, we can choose to control the various variables, such as generator power, generator speed and wind. The mathematical model of the system must be well known, when traditional tilt control usually use PI controller. In this paper, the control design was developed by the genetic algorithm [4].

Studied the optimal method of the control law to rotate wind generator's blades in order to increase the output power. Dynamic's wind generator can be described as a nonlinear mathematical model, in which the effect of input is variable wind speed. This model is used to develop the fuzzy regulator which is set its parameters by using genetic algorithm. The computational experiments have been shown that changes in the tilt angle of the wheel blades wind can significantly increase the output power at low and average wind speeds [5].

This paper shows the manufactured dual wind small turbine with two moving wings to change the tilt angle from $0^{\circ}$ to $14^{\circ}$ degree. Using a mechanical mechanism to control these movable wings electrically to control the angle to produce the best value of power generation by Genetic Algorithm (GA), used a device to reverse the rotor rotation to study multiple cases to achieve the best results and performance of the separation mechanism.

\section{Analysis of Power Produced From Dual Wind Turbine}

According to Betz theory, the maximum wind power is nearly $16 / 27$ of the obtainable energy in the wind while less wind axial speed by two-thirds through a singular rotor disc. Whatever, the process of wind turbines is transforming lower than $40 \%$ of wind energy to electrical energy. Thus, approximately $60 \%$ of probable wind energy evades without being used. . In fact, the energy in the wake of one rotary wake is large. Some of this energy might be extracted by constituting the other rotor in the wake. Since rotation behind first rotor rotates in reverse direction to the rotating direction of rotor, It should turn the other rotor in same direction that wake up efficiently the available energy extraction in its wake [6] Currently, the concept of contra is applied on boats airplanes and submarines in order to rise the efficiency, while the elimination of asymmetric torque is faced by traditional rotors.

From the fundamentals of physical basics of mass, momentum, and energy interchange, the movement of any fluid can be derived. The torque is responsible for the output power of wind turbine arising mostly because of the forces generated by the interaction of the blades with the wind. The output power of the turbine rotor and wind kinetic energy per unit time are given as below [7].

$$
P_{T}=T_{m} \cdot \omega
$$

$$
P_{W}=\frac{1}{2} \rho \cdot V_{0}^{3} \cdot A
$$

Where: $A=$ Swept area of the Blades $(\mathrm{m} 2), \mathrm{P}_{\mathrm{T}}=$ Output power from a turbine rotor $(\mathrm{W}), \mathrm{P}_{\mathrm{W}}=$ Wind kinetic energy per unit time $(\mathrm{W}), \mathrm{T}_{\mathrm{m}}=$ Mechanical torque at the turbine side (N.m), $V_{0}=$ Wind Velocity $(\mathrm{m} / \mathrm{s}), \rho=$ Air density at the hub height $\left(\mathrm{kg} / \mathrm{m}^{3}\right)$ and $\omega=$ Angular velocity $(\mathrm{rad} / \mathrm{sec})$.

\section{Experimental Work}

In this section, explained the practical aspect of manufacturing a wind power system in two cases, single and dual wind turbine blades, which include different secondary operations states. The main purpose of this is to find the best case of receiving wind energy and converting it into electrical power in the wind turbine. This experimental work can be divided into three main sections, namely the mechanical components section, the electrical components section and the last section is the control of the whole system and the extraction of all the values to be desired.

\subsection{Mechanical Components}

The mechanical components can be divided into three parts, the first part is front part to be placed in the direction of the expected wind, the second part is the rear part and third part is gearbox and three-phase permanent magnet synchronous generator, as shown in Figure (2). The front and rear parts is divided into, movable wing and non movable wing. All specifications and dimensions of the components will be handled according to their location as follows:

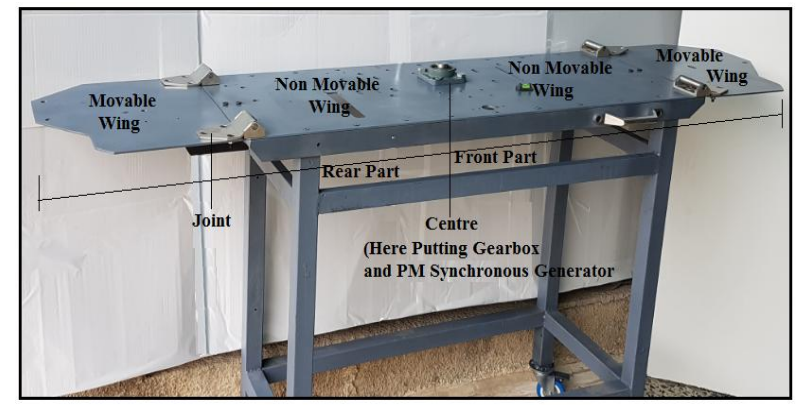

Fig. 2 The Simplified layout of The Manufactured Dual Wind Turbine

\subsubsection{Movable Wing of The Front Part}

The movable wing is important because it includes a new idea to be accomplished in this paper, it contains:

i-Set of blades (three blades) with the length $(82.5$ $\mathrm{cm})$ for each Model Number: NE-M3, The total diameter is about $(165 \mathrm{~cm})$ that made from $(\mathrm{PVC})$ and variable thickness and hub that the blades carry be with that dimensions an external diameter $(150 \mathrm{~mm})$ and internal diameter of $(16 \mathrm{~mm})$ as shown in 
Figures (3). Thickness of blade tip $3 \mathrm{~mm}$ and other side $4 \mathrm{~mm}$, thickness in the chord $4 \mathrm{~mm}$ and other side $8 \mathrm{~mm}$ and final in the root of blade $14.5 \mathrm{~mm}$.

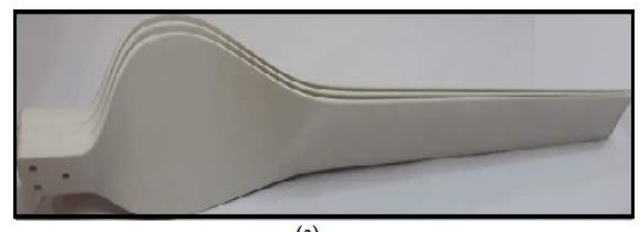

(a)

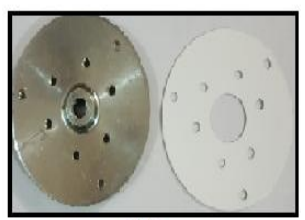

(b)

Fig. 3 Wind Turbine Blades Type KK342-500,

(a)-Set of Blades, (b)- The Hub of Wind Turbine.

ii- The movable wing base that dimensions

$(32 \mathrm{~cm} \times 40 \mathrm{~cm} \times 0.4 \mathrm{~cm})$.

iii- Figure (4) explains all that will be mentioned in (iii) to (v). Two ball bearings, that internal diameter (25mm), model P205,W/ Grease Zerk. Pillow, with manufactured bases of aluminum with dimensions (128 x 40 × $60 \mathrm{~mm})$.

iv- The shaft length $575 \mathrm{~mm}$, consist three parts with diameters (16mm, $25 \mathrm{~mm}$ and $28 \mathrm{~mm}$ ), made of mild steel material.

v- The movable wing shall be fixed with the non movable wing of the front and rear parts by help of two joints, it characterized by high durability and high tolerance to lift the moving part with full flexibility. This base moves from an angle $\left(0^{\circ}-14^{\circ}\right)$ by used this joints. Thus, blades will tend the same angle as the largest wind power possible to receive the note that the movement of this rule will be through the mechanism will be explained later.

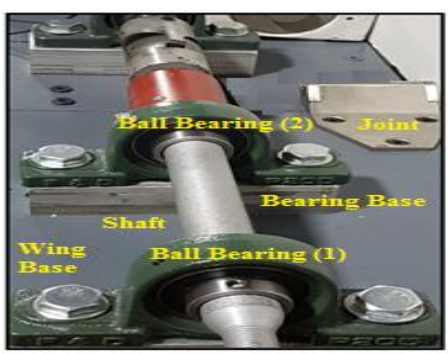

Fig. 4 Movable Wing of Front Part

vi-The movable wing in front and rear parts are raised by: (a)- Splined Shaft

(b)-Mechanism of Lifting the Movable Wings

(a)- Splined Shaft

Splined shaft as shown in Figure (5). These part consist of; hollow shaft with slots, length $(62 \mathrm{~mm})$ and external diameter $(43 \mathrm{~mm})$, one of the ends shall have an internal diameter of $(25 \mathrm{~mm}),(21 \mathrm{~mm})$ long, consisting of (6) slots. The second side without slots, inner diameter $(28 \mathrm{~mm})$. For the purpose of achieving the best performance to raise the movable wing on the presence of cardan joint, see Figure (6).

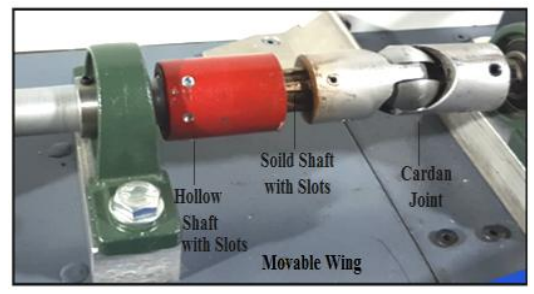

Fig. 5 Splined Shaft with Cardan Joint

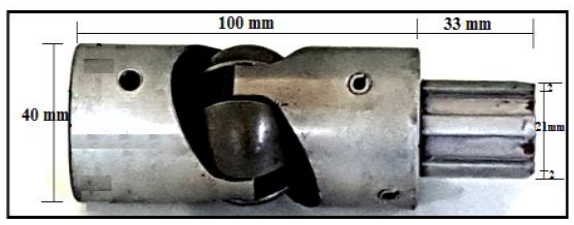

Fig. 6 Cardan Joint Type

(Single Universal Joint High Velocity )

\section{(b)- Mechanism of Lifting the Movable Wings}

The mechanical components of the mechanism of lifting the movable wings for the front and rear parts of the dual wind turbine in this work are identical to the specifications and measurements of the working mechanism. The mechanical mechanism of the lift wings of both sides works at one time and at an angle $\left(0^{\circ}-14^{\circ}\right)$, This mechanism consists of the following components; as shown in Figure (7).

-Two arms for lifting and dismounting for both sides are made of mild steel material.

-Screw rod to rise and descend wings length $285 \mathrm{~mm}$.

-Two rods working as shaft guide, with total length 285 $\mathrm{mm}$, screw outer diameter $16 \mathrm{~mm}$ and made of steel alloy.

-Two gears with chain, large size gear is a driver with teeth number 28, outer diameter $60 \mathrm{~mm}$ and inner diameter $8 \mathrm{~mm}$, small size gear is a driven with teeth number 24 , outer diameter $52 \mathrm{~mm}$ and inner diameter $12 \mathrm{~mm}$.

- Foundation working as the base to movement control of the mechanism with the following dimensions length $140 \mathrm{~mm}$, wide $40 \mathrm{~mm}$ and height $20 \mathrm{~mm}$, the foundation are placed two rods.

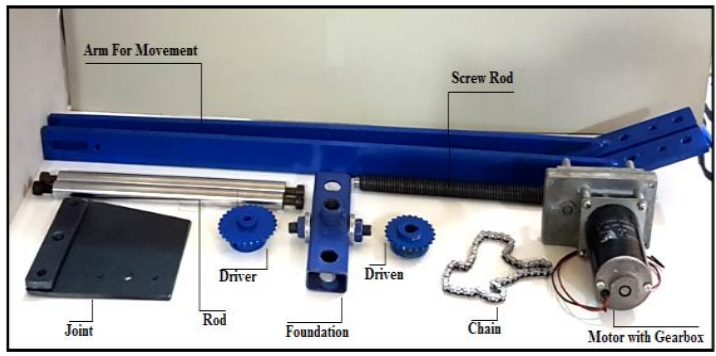

Fig. 7 Mechanism Components of Lifting Movable Wings 


\subsubsection{Movable Wing of the Rear Part}

The rear part is divided into two parts, movable wing and non movable wing, this set is characterized by the complexity of the design aimed at controlling the direction of rotation shaft carrier. All specifications and dimensions of the components will be handled according to their location as follows:

i- Sets of blades a symmetric with the front part.

ii- Hub that the blades carry which Featured they can be tightened in two cases, which match the angles between the front and rear parts, as well as when the deviation between blades of the front and rear. All components of this part are similar to which was mentioned in the front part.

\subsubsection{The Non Movable Wing of The Rear Part}

\section{i-Separated Mechansim For Rear Rotor}

The rotor of the rear part of the system manufactured in this work is separated from the rotor of the front part of the system completely by a mechanical hand mechanism as shown in Figure (8), but is sensitive whether the rear system is attached to the front system or is separated by a sensor.

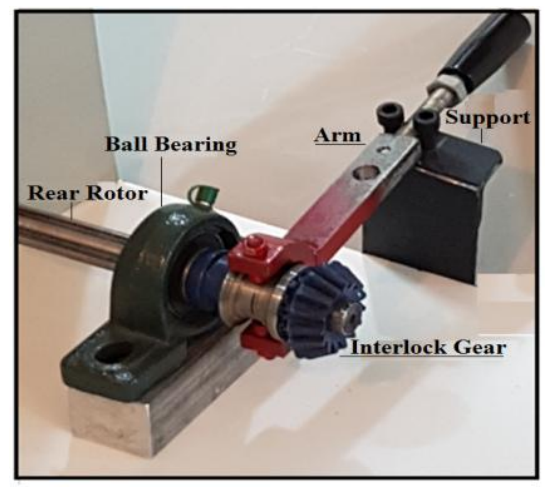

Fig. 8 Separated Mechansim For Rear Rotor

\section{ii- Reverse Rotation by Gear Box}

In this work, a set of operating conditions is studied. This requires the placing of a mechanical mechanism in the back of the system called the reversing system of the Model Name: ATV 009-sophie [8], which has the specifications specified in the table, in order to reverse the direction of rotation in any other direction. It is compatible with the direction of the axis rotation of the front part of the system. This mechanism is controlled by hand, but a sensor is set to feel the inward rotation as shown in the following Figure (9).

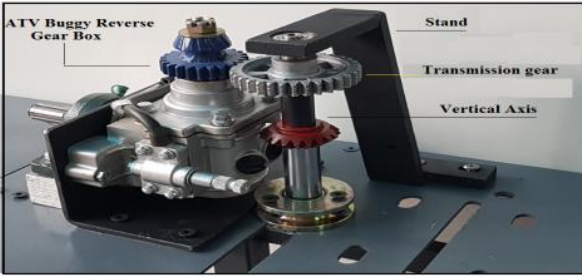

Fig. 9 ATV Buggy Reverse Gear Box, Model Name: ATV 009-sophie,[8].

For the purpose of the mechanical advantage of the use of the ATV-Buggy-Reverse-Gear-Box we attach a set of vertical axis gears to achieve and this cycle makes the system work well and perfect. Figure (10) shows The installation of the mechanical parts without blades installation and Figure (11) the manufactured dual wind turbines in this work.

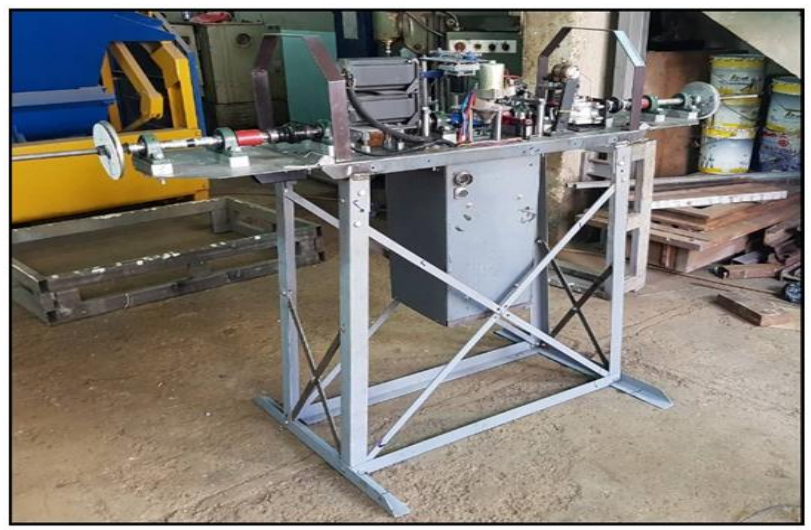

Fig. 10 The Installation of Mechanical Parts

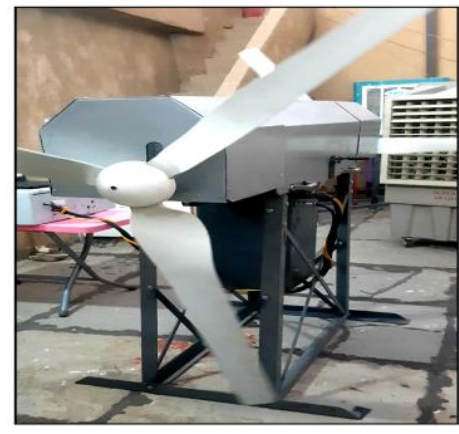

Fig. 11 Manufactured Dual Wind Turbines

\subsection{Motor to Lift up Gradually and Vice Versa The Wings of Dual Wind Turbine}

Mechanism is controlled electrically by lifting or lowering the two wings in same time according to the appropriate angle to receive the wind by the Double parallel axis motor two-axis forward and reverse motor model (SY104GF-3421L-47.8), belt reducer one shaft rotates forward and the other shaft reverses, see Figure (12), [9]. 


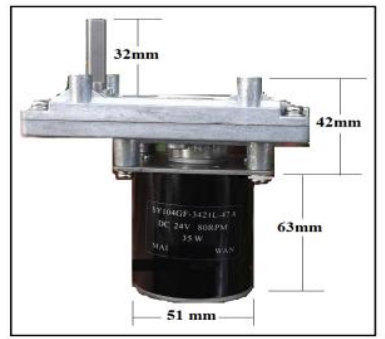

(a)

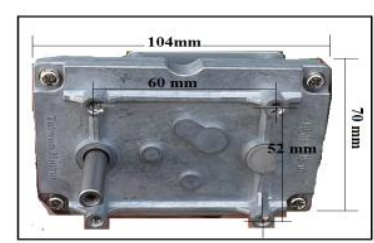

(b)
Fig. 12 Reverse Motor with Gearbox Type, (a)- Front View and (b)-Top View [9].

\section{Results and Discussion}

\subsection{Single Wind Turbine with Changeable Tilt Angles for the Movable Wing}

Table 1 was studied, in this case the operation mode of the system is ( SRWT) with changing the tilt angles of the movable wing is the base on which the blade was fixed and the angles changed from $0^{\circ}$ to $14^{\circ}$ as well as changing the simulation speed from 1 to $13 \mathrm{~m} / \mathrm{sec}$ or from $11 \mathrm{rpm}$ to $151 \mathrm{rpm}$. This table included changing in the angles according to the range mentioned above and it was found when the speed is $11 \mathrm{rpm}$ that the best value of electric power generated when the angle $\left(12^{\circ}\right)$. When comparing the power generated in this case found that the value $(2.95 \mathrm{~W})$. From observation of all results for different velocities it was found that the best angle to give the best value for GA was ranging from $12^{\circ}$ to $14^{\circ}$ and at the maximum speed $151 \mathrm{rpm}$ that the generating value was $(105.648 \mathrm{~W})$.

Table (1) Results of Single Rotor Wind Turbine with Tilt Angle of Movable Wing

(a) When rotation speed $11 \mathrm{rpm}$ and wind speed $0.95 \mathrm{~m} / \mathrm{sec}$

\begin{tabular}{|c|c|c|c|c|c|}
\hline \multirow[t]{2}{*}{$\begin{array}{c}\text { Tilt } \\
\text { Angle }\end{array}$} & \multicolumn{3}{|c|}{$\begin{array}{l}\text { Genetic Algorithm } \\
\text { (G.A) }\end{array}$} & \multicolumn{2}{|c|}{ Best Value } \\
\hline & $\begin{array}{l}\text { Volt } \\
\text { (V) }\end{array}$ & $\begin{array}{c}\text { Curre } \\
\text { nt } \\
\text { (I) }\end{array}$ & $\begin{array}{l}\text { Power } \\
\text { (W) }\end{array}$ & $\begin{array}{c}\text { Tilt } \\
\text { Angle }\end{array}$ & $\begin{array}{l}\text { Power } \\
\text { (W) }\end{array}$ \\
\hline 0 & 12.3 & 0.201 & 2.472 & \multirow[t]{15}{*}{12} & \multirow[t]{15}{*}{2.958} \\
\hline 1 & 12.2 & 0.203 & 2.481 & & \\
\hline 2 & 12.15 & 0.203 & 2.470 & & \\
\hline 3 & 12.3 & 0.201 & 2.472 & & \\
\hline 4 & 12.15 & 0.205 & 2.499 & & \\
\hline 5 & 12.2 & 0.201 & 2.452 & & \\
\hline 6 & 12.36 & 0.210 & 2.600 & & \\
\hline 7 & 12.3 & 0.208 & 2.558 & & \\
\hline 8 & 12.2 & 0.217 & 2.652 & & \\
\hline 9 & 12.41 & 0.217 & 2.697 & & \\
\hline 10 & 12.41 & 0.212 & 2.639 & & \\
\hline 11 & 12.36 & 0.217 & 2.686 & & \\
\hline 12 & 12.41 & 0.238 & 2.958 & & \\
\hline 13 & 12.41 & 0.233 & 2.900 & & \\
\hline 14 & 12.15 & 0.236 & 2.868 & & \\
\hline
\end{tabular}

(b)-Tilt Angle $\left(0^{0}-14^{0}\right)$

\begin{tabular}{|c|c|c|c|c|c|c|}
\hline \multirow[t]{2}{*}{ rpm } & \multirow{2}{*}{$\begin{array}{l}\text { Wind } \\
\text { Speed } \\
(\mathrm{m} / \mathrm{s})\end{array}$} & \multicolumn{3}{|c|}{ Genetic Algorithm (G.A) } & \multicolumn{2}{|c|}{ Best Value } \\
\hline & & $\begin{array}{l}\text { Volt } \\
(\mathrm{V})\end{array}$ & $\begin{array}{c}\text { Curre } \\
\text { nt } \\
\text { (I) }\end{array}$ & $\begin{array}{c}\text { Power } \\
\text { (W) }\end{array}$ & $\begin{array}{c}\text { Tilt } \\
\text { Angle }\end{array}$ & $\begin{array}{c}\text { Powe } \\
r \\
(W)\end{array}$ \\
\hline 16 & 1.382 & 12.36 & 0.408 & 5.042 & 12 & 5.042 \\
\hline 20 & 1.727 & 12.36 & 0.497 & 6.146 & 14 & 6.146 \\
\hline 23 & 1.987 & 12.36 & 0.547 & 6.765 & 3 & 6.765 \\
\hline 25 & 2.159 & 12.3 & 0.610 & 7.514 & 3 & 7.514 \\
\hline 32 & 2.764 & 12.2 & 0.632 & 7.715 & 0 & 7.715 \\
\hline 36 & 3.019 & 12.2 & 0.696 & 8.493 & 14 & 8.493 \\
\hline 41 & 3.542 & 12.2 & 0.914 & 11.160 & 0 & 11.16 \\
\hline 48 & 4.146 & 12.25 & 1.060 & 12.994 & 14 & 12.99 \\
\hline 59 & 5.097 & 12.3 & 1.354 & 16.654 & 13 & 16.65 \\
\hline 71 & 6.133 & 12.25 & 1.674 & 20.515 & 0 & 20.51 \\
\hline 82 & 7.084 & 12.15 & 2.056 & 24.982 & 13 & 24.98 \\
\hline 93 & 8.034 & 12.15 & 2.351 & 28.573 & 1 & 28.57 \\
\hline 105 & 9.071 & 12.15 & 2.655 & 32.260 & 14 & 32.26 \\
\hline 116 & 10.02 & 12.2 & 3.475 & 42.402 & 12 & 42.40 \\
\hline 128 & 11.05 & 12.66 & 4.433 & 56.129 & 14 & 56.12 \\
\hline 139 & 12.00 & 12.96 & 6.055 & 78.475 & 12 & 78.47 \\
\hline 151 & 13.04 & 13.17 & 8.021 & 105.64 & 14 & 105.6 \\
\hline
\end{tabular}

\subsection{The Cases Studied of the Manufactured Dual Wind Turbine}

\subsubsection{Rotation in the Same Direction of Front and Rear Rotors}

Table 2 shows the power generated by the rotation of the front and rear blades in the same direction, as well as changing the tilt angles of the movable wings from $\left(0^{\circ}-14^{\circ}\right)$. This case is important in this work as the manufactured system will work more balanced. Position matching of front blades with rear blades and the work of starter motor will be clear in this case more than the rest of the cases of rotation. It was found that the power obtained from each rotational speed has a tilt angle where the generated energy is highest when calculated in a genetic algorithm. Note from the Table (2) that there is a variation in the tilt angles from the tilt angles between $\left(0^{\circ}-14^{\circ}\right)$ and this means that the performance of the system does not follow the context of one action, the maximum generated power was obtained at speed (rpm151), tilt angle $\left(12^{\circ}\right)$ and power $(124.223 \mathrm{~W})$. 
Table 2 Rotation of Dual Wind Turbine In The Same Direction

\begin{tabular}{|c|c|c|c|}
\hline \multirow{2}{*}{$\begin{array}{c}\text { Rotatio } \\
\text { n Speed } \\
(\mathrm{rpm})\end{array}$} & $\begin{array}{c}\text { Wind } \\
\text { Speed } \\
(\mathrm{m} / \mathrm{s})\end{array}$ & \multicolumn{2}{|c|}{$\begin{array}{c}\text { Best Value From } \\
\text { Genetic Algorithm }\end{array}$} \\
\cline { 3 - 4 } & & $\begin{array}{c}\text { Angle } \\
(\text { degree })\end{array}$ & $\begin{array}{c}\text { Power } \\
(\mathrm{W})\end{array}$ \\
\hline 11 & 0.950 & 2 & 3.709 \\
\hline 16 & 1.382 & 13 & 5.956 \\
\hline 20 & 1.727 & 9 & 7.234 \\
\hline 23 & 1.987 & 5 & 8.546 \\
\hline 25 & 2.159 & 6 & 9.057 \\
\hline 32 & 2.764 & 11 & 11.563 \\
\hline 36 & 3.110 & 5 & 12.678 \\
\hline 41 & 3.542 & 14 & 13.894 \\
\hline 48 & 4.146 & 0 & 16.987 \\
\hline 59 & 5.097 & 1 & 19.872 \\
\hline 71 & 6.133 & 14 & 23.673 \\
\hline 82 & 7.084 & 13 & 27.983 \\
\hline 93 & 8.034 & 12 & 31.453 \\
\hline 105 & 9.071 & 11 & 37.765 \\
\hline 116 & 10.021 & 5 & 52.984 \\
\hline 128 & 11.058 & 1 & 70.456 \\
\hline 139 & 12.008 & 14 & 102.566 \\
\hline 151 & 13.045 & 12 & 124.223 \\
\hline & & & \\
\hline
\end{tabular}

\subsubsection{Torque Production of the Dual Wind Turbine}

Table (3) showing the amount of torque that will be consumed to produce power from the simulation motors at rotation of dual wind turbine in the same direction. The process of connecting the simulation motors to the front rotor of the system is a parallel connection which means that the total torque generated by the simulation motors will be divided into a torque for the front and rear rotors and sufficient torque for the input of upper gearbox to turn it into a high rotational speed at the output. From the Equation (1) calculated the torque values.

Table 3 Theoretical Torque Obtained From Simulation Motors

\begin{tabular}{|c|c|c|}
\hline $\begin{array}{c}\text { Rotation Speed } \\
(\mathrm{rpm})\end{array}$ & $\begin{array}{c}\text { Power } \\
(\mathrm{W})\end{array}$ & $\begin{array}{c}\text { Torque } \\
(\mathrm{N} . \mathrm{m})\end{array}$ \\
\hline 11 & 3.709 & 3.221 \\
\hline 16 & 5.956 & 3.556 \\
\hline 20 & 7.234 & 3.455 \\
\hline 23 & 8.546 & 3.549 \\
\hline 25 & 9.057 & 3.461 \\
\hline 32 & 11.563 & 3.452 \\
\hline 36 & 12.678 & 3.364 \\
\hline 41 & 13.894 & 3.237 \\
\hline 48 & 16.987 & 3.381 \\
\hline 59 & 19.872 & 3.217 \\
\hline 71 & 23.673 & 3.185 \\
\hline 82 & 27.983 & 3.260 \\
\hline 93 & 31.453 & 3.231 \\
\hline 105 & 37.765 & 3.436 \\
\hline 116 & 52.984 & 4.363 \\
\hline
\end{tabular}

\begin{tabular}{|c|c|c|}
\hline 128 & 70.456 & 5.258 \\
\hline 139 & 102.566 & 7.049 \\
\hline 151 & 124.223 & 7.859 \\
\hline
\end{tabular}

\subsubsection{Rotation of Front and Rear Wind Turbine In The} Reverse Directions

The Table (4) shows the best values of electrical power generated at a different tilt angles and speeds. In this case that the position of the front blades cannot be in a match with the rear blades. When comparing this table with the previous Table, it was found that the value of power generation is less because there is a resistance in the rotation of the rear blades, although the rear rotates at a higher speed. The best tilt angles of the movable wings ranging from $\left(0^{\circ}-14^{\circ}\right)$ similar to the previous Table (3). Therefore, the previous case is considered to be better, but this situation can be used when the wind is variable in direction and velocity.

Table (4) Rotation of Front and Rear Wind Turbine In The Reverse Directions

\begin{tabular}{|c|c|c|c|c|}
\hline $\begin{array}{c}\text { Rotation } \\
\text { Speed } \\
(\mathrm{rpm})\end{array}$ & $\begin{array}{c}\text { Wind } \\
\text { Speed } \\
(\mathrm{m} / \mathrm{s})\end{array}$ & $\begin{array}{c}\text { Tilt } \\
\text { Angles } \\
\text { (degree })\end{array}$ & \multicolumn{2}{|c|}{$\begin{array}{c}\text { Best Value From } \\
\text { Genetic Algorithm }\end{array}$} \\
\cline { 4 - 5 } & & & $\begin{array}{c}\text { Angle } \\
(\text { degree })\end{array}$ & $\begin{array}{c}\text { Power } \\
(\mathrm{W})\end{array}$ \\
\hline 11 & 0.950332 & $\left(0--14^{\circ}\right)$ & 3 & 3.407491 \\
\hline 16 & 1.382301 & $\left(0--14^{\circ}\right)$ & 14 & 5.126571 \\
\hline 20 & 1.727876 & $\left(0--14^{\circ}\right)$ & 10 & 6.39846 \\
\hline 23 & 1.987057 & $\left(0--14^{\circ}\right)$ & 4 & 7.399773 \\
\hline 25 & 2.159845 & $\left(0--14^{\circ}\right)$ & 5 & 8.043231 \\
\hline 32 & 2.764602 & $\left(0--14^{\circ}\right)$ & 10 & 10.11269 \\
\hline 36 & 3.110177 & $\left(0--14^{\circ}\right)$ & 6 & 11.37677 \\
\hline 41 & 3.542146 & $\left(0--14^{\circ}\right)$ & 13 & 12.88208 \\
\hline 48 & 4.146902 & $\left(0--14^{\circ}\right)$ & 0 & 15.08147 \\
\hline 59 & 5.097234 & $\left(0--14^{\circ}\right)$ & 0 & 18.12734 \\
\hline 71 & 6.13396 & $\left(0--14^{\circ}\right)$ & 13 & 22.21695 \\
\hline 82 & 7.084291 & $\left(0--14^{\circ}\right)$ & 13 & 25.65901 \\
\hline 93 & 8.034623 & $\left(0--14^{\circ}\right)$ & 11 & 29.63189 \\
\hline 105 & 9.071349 & $\left(0--14^{\circ}\right)$ & 12 & 34.70709 \\
\hline 116 & 10.02168 & $\left(0--14^{\circ}\right)$ & 4 & 46.52293 \\
\hline 128 & 11.05841 & $\left(0--14^{\circ}\right)$ & 0 & 62.78745 \\
\hline 139 & 12.00874 & $\left(0--14^{\circ}\right)$ & 13 & 96.03229 \\
\hline 151 & 13.04546 & $\left(0--14^{\circ}\right)$ & 11 & 115.1456 \\
\hline & & & & \\
\hline
\end{tabular}

\section{Conclusions}

From the results of this work the following conclusions can be obtained:

1- The torque value obtained from the rotation of the dual wind turbine in the same direction was calculated theoretically at the maximum rotational speed (151 r.p.m) where the torque value was 7.859 N.m. at the tilt angle is about $12^{\circ}$.

2- When operation of the moving wings of the dual wind turbine found that there is an increase in the power generation, but this increase depends on the amount of tilt angle of the movable wing support these blades. 
Because the value of friction in the rotors and the splined shaft will be lower.

3- Separation mechanism and rotation reversing device proved efficient and accurate performance.

\section{References}

[1]- Wei Y., Ahmet O, Wei T. and Hui H., "An Experimental Study on the Effects of Relative Rotation Direction on the Wake Interferences among Tandem Wind Turbines", Science China Physics, Mechanics and Astronomy, 2010, 57, 5, 556-573.

[2]- Priyono S. and Deny B. S., "Design and Blade Optimization of Contra Rotation Double Rotor Wind Turbine", International Journal of Mechanical and Mechatronics Engineering (IJMME), 2011, 11, 1, 47-64.

[3]- Ling L.Y., King H.L. and Su S.W., " Effects of Blade Pitch, Rotor Yaw, and Wind-Wave Misalignment on a Large Offshore Wind Turbine Dynamics in Western Gulf of Mexico Shallow Water in 100-Year Return Hurricane", Journal of Offshore Mechanics and Arctic Engineering, 2017, 139, 1.

[4]. Muhannad Z. Khelifa, Ali H. Z'aibel and Haider Kh.Mehbas," Dynamically Loaded Analysis of The Adjustable Hydrodynamic Pads Bearing “,Eng.\&Tech., 2008, 26, 8,

[5] -Mikhail B. and Vladislav Sh., "Genetic Algorithm Optimization For Pitch Angle Control of Variable Speed Wind Turbines", $12^{\text {th }}$ International ScientificTechnical Conference on Electro mechanics and Robotics, 2017.

[6]- Riadh H., Voicu G., Yue Y., Charles B., and Pierre G.," Performance Testing and Control of a Small Wind Energy Converter", Sixth IEEE International Symposium on Electronic Design, Test and Application, Queenstown, New Zealand Jan. 2017,17-19.

[7] - Riadh H., Voicu G., Yue Y., Charles B., and Pierre G.," Performance of a Contra-rotating Small Wind Energy Converter", International Scholarly Research Network (ISRN), Mechanical Engineering, 2017Article ID 828739, 17,6.

[8].https://www.made-in-china.com

[9]. https://item.taobao.com 